\title{
Prevalence of oral lesions caused by removable prosthetics
}

\author{
Andreza Maria de Oliveira Filgueiras \\ Postgraduate Program in Dentistry, School of Dentistry, Universidade Federal Fluminense, Nova Friburgo, Rio de Janeiro, Brazil \\ Helene Santos Carvalho Pereira \\ Ruth Tramontani Ramos \\ Policlinic Piquet Carneiro, School of Dentistry, Universidade do Estado do Rio de Janeiro, Rio de Janeiro, Brazil \\ Bruna Lavinas Sayed Picciani \\ Thays Teixeira de Souza \\ Lívia Maria dos Santos Izahias \\ Postgraduate Program in Pathology, School of Medicine, Universidade Federal Fluminense, Niteroi, Rio de Janeiro, Brazil \\ Geraldo Oliveira Silva-Junior \\ Marília Heffer Cantisano \\ Policlinic Piquet Carneiro, School of Dentistry, Universidade do Estado do Rio de Janeiro, Rio de Janeiro, Brazil \\ Department of Diagnostic and Therapeutic, School of Dentistry, Universidade do Estado do Rio de Janeiro, Rio de Janeiro, Brazil \\ - Os autores declaram que não há conflito de interesse.
}

\section{Abstract}

The present study aimed to investigate the prevalence of injuries caused by removable prostheses in patients of clinical specialization in dentistry. Of 598 patients, $175(29 \%)$ had some type of associated injury. The lesions found included erythematous candidiasis, inflammatory fibrous hyperplasia, inflammatory papillary hyperplasia, traumatic ulcer, angular cheilitis, irritative keratosis, and denture stomatitis. Inflammatory fibrous hyperplasia was the most prevalent lesion, found in 88 patients (50\%),followed by erythematous candidiasis in 75 patients (43\%). Of the total number of injured patients, 141 (81\%) were women and 34 (19\%) were men, and 101 patients (58\%) were Caucasian and $37(21 \%)$ were black. Most lesions were located in the upper alveolar ridge and the hard palate. The most widely used type of prosthesis was full upperprosthesis with 84 users (48\%). The average usage time for all prostheses was 17 years (SD \pm 13 ). Average patient age was 62 years (SD \pm 14$)$. The prevalence of injuries caused by removable prostheses is high, and prolonged use of the device and the presence of oral lesions are strongly associated. Moreover, women represent the largest number of users of the prostheses and therefore carry the majority of the injuries.

Keywords:removable prosthodontics; oral lesions; hyperplasia; stomatitis.

\section{Introduction}

B razil is going through a population aging period, with a steady and continuous increase of Brazilian life expectancy. ${ }^{1}$ Some studies show that as the current elderly population comes from a time when health promotion was not a high priority,many of today's seniors will soon have poor oral health.The elderly population in Brazil contains $68 \%$ edentulous individuals. ${ }^{2,3}$ In this context, total or partial dentures are important tools in the rehabilitation of patients who have suffered tooth loss, in order to obtain better quality of life. ${ }^{3,4}$

Even with the use of rigid clinical and laboratory techniques to manufacture the prosthesis, the oral mucosa can be affected by injuries that arise in association with the use of these prostheses.It is already widely reported that several factors associated with removable dentures, such as poor preparation of the prosthesis, bad oral hygiene, and maladjustment by long use and use throughout the day, are able to induce a change in the oral mucosa. Lesions commonly associated with the use of the removable dentures are: prosthetic stomatitis, traumatic ulcers, fibrous hyperplasia, and candidiasis. The lesions caused by the prosthesis usually follow a route of slow and asymptomatic evolution, passing unnoticed by patients who do not seek treatment.The injury may continue to worsen, making the course of treatment more complex. It is the professional's responsibility to counsel patients about the importance of cleaning the prosthesis, as well as its removal for a part of the day. Patients should also be counseled on theregular maintenance and periodic exchanges associated with the prosthesis. ${ }^{5-7}$

This study aimed to carry out a review of the medical records of patients who used removable prostheses that were served at a clinic of specialization in Stomatology, School of Dentistry, State University of Rio de Janeiro, between 2003 and 2015. The medical records were reviewed in order to describe the profile of these patients and lesions caused by the use of prostheses.

\section{Material and Methods}

A prospective and cross-sectional study was conducted by reviewing medical records of patients who used some type of removable prosthesis andwere treated at the Clinic of Specialization in Stomatology/Policlinic Piquet Carneiro, School of Dentistry of State University of Rio de Janeiro from 2003 to 2015. Demographic and clinical data collected from patients corresponded to: name, gender / sex, skin color, age, use of removable prosthesis, length of use, and occurrence of oral lesions. All data and information obtained were included in the database (Microsoft Of- 
fice Excel 2007) for analysis. The statistical description of the variables were made using proportions (when the variables were categorical), and mean, standard deviation, minimum and maximum values, median, and mode (when the variables were numerical). To evaluate the differences between two or more categorical variables, the chi-square test was used (Fisher exact test and Pearson); for numerical variables, the Student's t-test was used. Statistical analysis was aided by SPSS software (SPSS Incorporation) version 20.0 and statistical decisions were taken at a significance level of $p=0.05$ (5\%). The study was approved by the Ethics Committee in Research with the CEP registration number 020/09.

\section{Results}

The sample consisted of 598 patients who used removable prostheses. Of these patients, 116 (19\%) were male and $482(81 \%)$ were female. Their ages ranged from 29 to 91 years, with an average age of 62 years (SD = 13), median 62 and mode 67; the most prevalent age group was of 61-70 years.Skin color was evaluated in only 577 patients, with white being the most frequent with 348 patients (60\%), followed by black with 142 patients (25\%)and grizzly with 87 patients (15\%). Of the 598 patients, 423 (71\%) had no lesions associated with the use of a removable prosthesis and 175 (29\%) patients had some type of lesion.We observed a significant difference when comparing the use of a prosthesis and the appearance of lesions $(\mathrm{p}<0.001)$, as well as when evaluating the frequency distribution associated with the lesion and age of the subjects $(p=0.013)$, indicating that long-term prosthesis use may be indicative of the onset of lesion. We did not find a statically significant association between the presence of lesions and skin color or sex (Table 1).

Regarding the type of removable prosthesis, the most frequent was the total prosthesis with 84 (43\%) patients. Seven patients (4\%) used lower total prosthesis and 63 (32\%) used both total prosthesis upper and lower. The upper partial prosthesis was present in 15 patients (8\%) and 2 patients (1\%) used both the upper and the lower partial, while 26 patients(12\%) used only the lower partial prosthesis (Figure 1). The average wear time of the removable prosthetics was 17 years $(S D=13$ years). Regarding the anatomical location, the highest prevalence of injuries caused by prosthesis occurred on the palate with 96 cases (48\%), followed by the upper alveolar ridge with $37(19 \%)$ and lower alveolar ridge with 25 cases (13\%)(Figure 2). Of the injuries described in the records, the most common was inflammatory fibrous hyperplasia, which occurred in 88 patients, followed by erythematous candidiasis, occurring in 75 patients (Figure 1). Other recorded lesions include traumatic ulcer in 16 patients, angular cheilitisin 13 patients, irritative keratosis in 6 patients, inflammatory papillary hyplerplasiain 6 patients, pseudomembranous candidiasis in 4 patients, and prosthetic stomatitis in 7 patients (Figure 3 ).

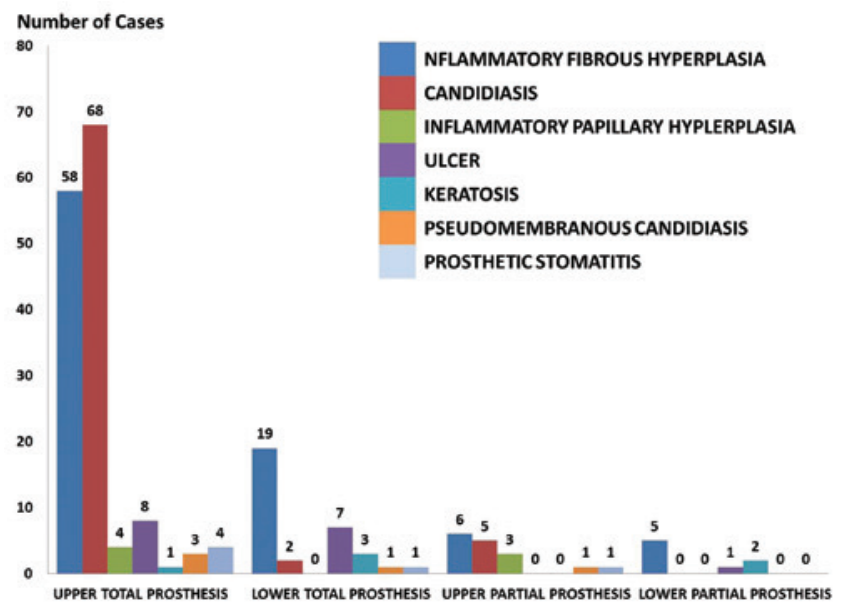

Figure 1. Distribution of oral lesions caused by prosthesis according to the type of dental prosthesis

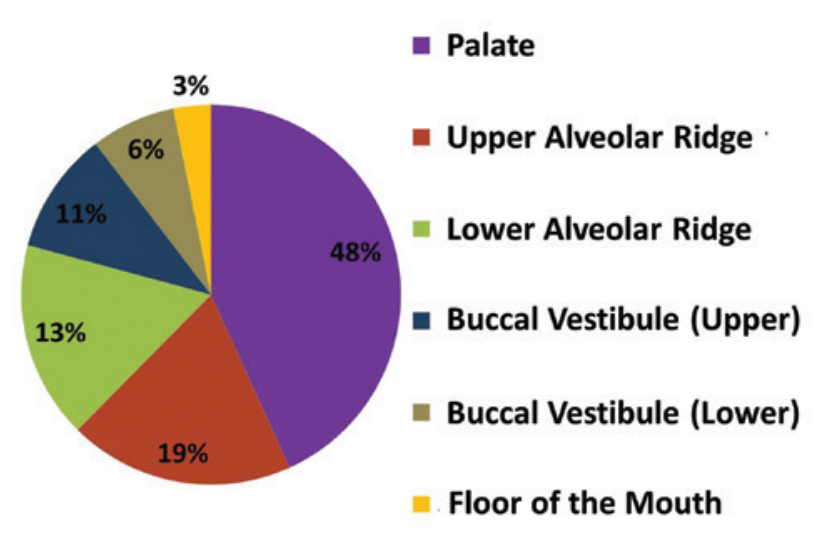

Figure 2. Distribution of lesions caused by prosthesis according to the anatomical location 

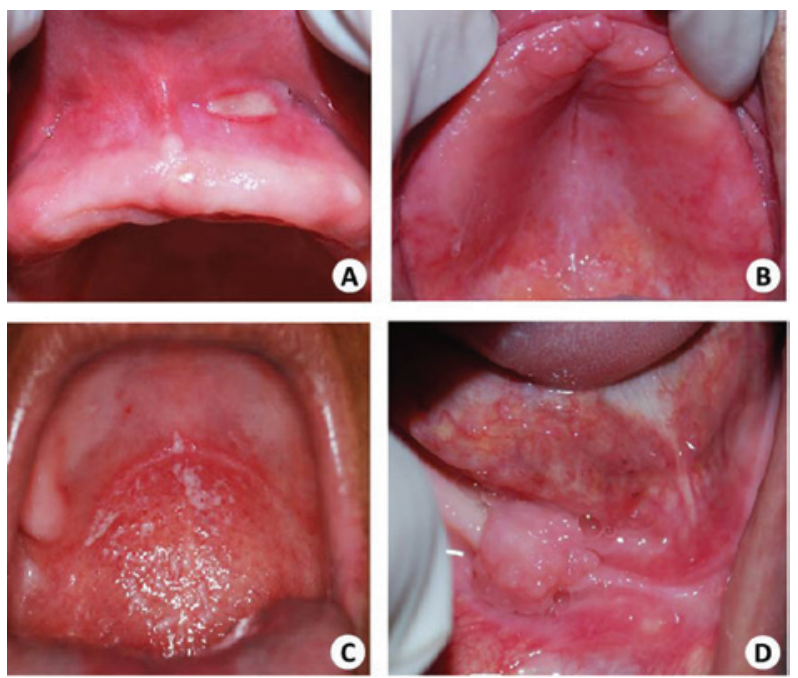

Figure 3. Clinical aspects of lesions caused by the use of removable prosthesis. A - traumaticulcer; B - Prosthetic stomatitis; C - Candidiasis Erythema and Pseudomembranous; D Fibrous Hyperplasia Inflammatory

Table 1. Distribution of demographic and clinical data of patients served at a clinic of specialization in Stomatology in a period from 2003 to 2015

\begin{tabular}{|c|c|c|c|c|c|c|}
\hline \multirow[b]{2}{*}{ Variable } & \multirow{2}{*}{ Category } & \multicolumn{2}{|c|}{ With Lesion } & \multicolumn{2}{|c|}{ Without Lesion } & \multirow{2}{*}{ p-value } \\
\hline & & $N=175$ & $\%$ & $\mathrm{~N}=423$ & $\%$ & \\
\hline \multirow{2}{*}{ Gender } & Female & 141 & 24 & 341 & 57 & \multirow{2}{*}{$0.903^{+}$} \\
\hline & Male & 34 & 6 & 82 & 13 & \\
\hline \multirow{3}{*}{ Skin color } & White & 101 & 17 & 247 & 41 & \multirow{3}{*}{$0.986^{++}$} \\
\hline & Grizzly & 29 & 5 & 58 & 10 & \\
\hline & Black & 37 & 6 & 105 & 17 & \\
\hline \multirow{3}{*}{$\begin{array}{c}\text { Age } \\
\text { (years) }\end{array}$} & Average \pm SD & \multicolumn{2}{|c|}{$62 \pm 14$} & \multicolumn{2}{|c|}{$62 \pm 12$} & \multirow{3}{*}{$0.986^{++}$} \\
\hline & Median & \multicolumn{2}{|c|}{64} & \multicolumn{2}{|c|}{62} & \\
\hline & Mode & \multicolumn{2}{|c|}{57} & \multicolumn{2}{|c|}{74} & \\
\hline \multirow{2}{*}{$\begin{array}{c}\text { Usage of the Removable Total } \\
\text { Prosthesis }\end{array}$} & Absent & 22 & 4 & 22 & 19 & \multirow{2}{*}{$<0.001^{+}$} \\
\hline & Present & 153 & 26 & 153 & 52 & \\
\hline
\end{tabular}

\section{Discussion}

After analyzing the results obtained in this study, it was observed that lesions associated with the use of removable prostheses were more prevalent in women (141 cases, 24\%); however, women represented the majority of the sample (482; 81\%) and, when compared with the men's lesion carrier group (34 cases, 6\%), we did not find statistically significant differences in the prevalence of injuries based on gender. This study corroborates most of the reports published in the literature, correlating the higher prevalence of lesions in females. ${ }^{3,5,8}$ This finding suggests two hypotheses: 1) women by pathophysiological reasons, hormonal or not, more often incur this type of injury; or 2) the distribution of the lesions studied in the population would occur homogeneously, however, when presented with an oral health problem, women seek treatment more frequently than men. ${ }^{9}$

This studynoted that most users of removable prosthesis are elderly (62 \pm 14 years). Several authors claim that with advancing age, there is a decrease in salivary flow that can occasionally, in prothesis wearers, cause pain, tongue grip on the prosthesis base, or lack of restraint, all of which can form oral lesions. This problem is solved by water intake by the patient, as well as conducting procedures stimulating salivary flow and the use of artificial saliva.These interventions, as well as indispensable periodic consultations to a stomatologist or dentist who cares for elderly people, may lead to better management of this condition. ${ }^{9,10}$ 
In the present study, there were a total of 348 patients (58\%) of white skin color, $142(23 \%)$ black, and 87 (15\%) of grizzly skin color. Our results are coincident with those presented by Baroni et al. (2014) in a descriptive study about lesions caused by removable prostheses in patients. When they analyzed ethnicity, it was noted that the concentration of cases was greatest in individuals of white skin color. ${ }^{11}$

Among the prostheses used in the group of patients who had some kind of lesion, the upper total prosthesis was the most commonly associated with lesions, which explains the presence of the majority of the described lesions on the palate. Often patients have difficulty adapting to a lower prosthesis, due to the pattern of bone reabsorption, which explains the high frequency of this type of prosthesis producing lesions on the palate. However, this was not confirmed in the study Baroni et al. (2014) and Alves \& Gonçalves (2005), which concluded that the prevalence of injuries caused by removable prostheses are in the bottom of the buccal vestibule..$^{11,12}$

Dentures are often related to the appearance of various lesions of the oral mucosa, whether due to a chronic trauma or by changing the quantity and quality of bacterial biofilms. ${ }^{3,8-11}$ The hyposalivation, for example, which occurs by the use of certain medications or advancing age, causes reduction in retention of the prosthesis, which can cause pain and tongue grip on the basis of prosthesis. This lack of retention may contribute to the formation of lesions in the oral mucosa, such as inflammatory fibrous hyperplasia, or even promote the appearance of opportunistic infections such as candidiasis. ${ }^{12}$

This study found in a sample of 598 removable prosthesis wearers, a total of 175 (29\%)lesions associated with the use of prostheses, a relatively low number compared to previous studies in the literature., ${ }^{9,13,14}$ Perhaps this fact can be explained by way of prosthesis confection, reducing irregularities, and with better adaptation, reducing the retention of biofilms and chronic trauma. ${ }^{15}$ However, the quality and hygiene of the prosthesis were not evaluated in this study.

The average age in the group of patients who had lesions and those who did not was the same, but the standard deviation of the group with lesions was larger, providing a greater age variation in the group of patients with lesions.The age that most frequently appeared in the group of patients with lesions was 57 years, whilethe age appearing most frequently in the group of uninjured patients was 74 years, which confirms that advancing age is not a causative factor to the appearance of lesions, as opposed to other factors such as length of time with the prosthesis, cleaning, and adaptation. ${ }^{14}$

The palate was the most affected area, followed by the superior alveolar ridge, which is likely explained by the fact that most injuries are caused by the upper total prosthesis and also for the already reported preference of certain lesions by the palate.

The main lesions that affect the oral mucosa and are related to the use of removable prostheses are inflammatory fibrous hyperplasia, candidiasis, prosthetic stomatitis, and cheilitis angular. ${ }^{8,10,13}$ Several authors affirm that prosthetic stomatitis is the most commonly observed lesion; ${ }^{3,5,14,16}$ however, in our study,the inflammatory fibrous hyperplasia was the most frequent lesion, corroborating the results of Medeiros (2015) and Jainkittivong (2010). ${ }^{3,15}$ This controversial fact can be attributed to the difficulty in differentiatingerythematous candidiasis and prosthetic stomatitis, as many scholars affirm that the term "chronic atrophic candidiasis" and prosthetic stomatitis are synonymous. ${ }^{16-18}$ It is debated whether prosthetic stomatitis is an infection by Candida albicans or is a reaction due to improper prosthesis confection which may be generating a trauma, allergies to the prosthesis base, inadequate polymerization of acrylic resin, or a host response to microorganisms that colonize the prosthesis base. ${ }^{19}$ In our study, we separate the prosthetic stomatitis and erythematous candidiasis according to Neville et al. (2008) and perhaps, for this reason, we find fewer of these lesions, contrary to previous findings..$^{3,5,14,16,19-21}$ A citopathological exam could help to distinguish these lesions, leading to diagnosis and adequate treatment.

\section{Conclusion}

Oral lesions caused by removable prostheses, especially inflammatory fibrous hyperplasia, are common in women between 61 and 70 years old, and are directly related to the continued use of the prosthesis. Therefore, it is of paramount importance that the dentist instruct the patient on the importance of proper hygiene and duration time of the use of prosthesis, as well as have periodic consultations with the patient in order to detect and diagnose lesions early, avoiding aggressive treatments that can affect the quality of life of these patients. 


\section{Referências ::}

1- Tibério D, Botti MTRS, Ramos LR. Estado periodontal e necessidade de tratamento em Idosos. RevRegAracatubaAssoc Paul CirDent. 2005;59(1):5-20.

2- Olchik MR, Ayres A, Presotto M, Baltezan RL, Gonçalves AK. O impacto do uso de prótese dentária na qualidade de vida de adultos e idosos. Revista Kairós Gerontologia. 2013;16(5):107-21.

3- Medeiros FCD, Araújo-Silva TF, Ferreira KA, Oliveira-Moura JMB, Cavalcanti-Lima IP, Guerra-Seabra EJ. Uso de prótese dentária e sua relação com lesões bucais. Rev.Salud Pública. 2015; 17(4):603-11.

4- Kupp LI, Sheridan PJ. Denture sore mouth. DermatolClin. 2003;21:115-22

5- Zissis A, Yannikakis S, Harrison A. Comparison of denture stomatitis prevalence in 2 population groups. Int J Prosthodont. 2006;19(6):621-5.

6- Cakan U, Yuzbasioglu E, Kurt H, Kara HB, Turunç R, Akbulut A, et al. Assessment of hygiene habits and attitudes among removable partial denture wearers in a university hospital. Nigerian Journal of Clinical Practice. 2016;18:511-5.

7- Araújo LMP, Cruz MJC, Meneses SS. Materiais e Métodos utilizados na higienização de próteses totais: Revisão da Literatura. Revista Interfaces Saúde, Humanas e Tecnologia. 2016;3(9):18-24.

8- Teles JACF. Lesões na cavidade oral associadas ao uso de prótese parcial removível. Faculdade de Ciências Médicas. Universidade Fernando Pessoa, 2010 .

9- Canger EM, Celenk P, Kayipmaz S. Denture-related hyperplasia: a clinical study of a Turkish population group. Braz Dent J. 2009;20(3):243-8.

10- Barbosa TP, Santana TS, Júnior RM, Batista JR, Silveira LF, Freitas AP. Lesões bucais associadas ao uso de prótese total. Rev. SaúdeCom. 2011;7(2):133-42.

11- Baroni J, Silva SO, Carli BMG, Linde MS, Carli JP. Alterações bucais causadas pelo uso de próteses removíveis - levantamento epidemiológico dos casos encontrados em um Serviço de Diagnóstico Histopatológico do
Sul do Brasil. Salusvita, Bauru. 2014;33(2):243-56.

12- Alves DLN. Candidaspp. e Prótese Dentária Removível: Interações de Relevância Clínica - Revisão Bibliográfica. Faculdade de Ciências Médicas. Universidade Fernando Pessoa, 2009.

13- Fonseca P, Areias C, Figueiral MH. Higiene de próteses removíveis. Revista Portuguesa de Estomatologia, Medicina Dentária e Cirurgia Maxilofacial.2007;48(3):141-6.

14- Bianchi CMPC, Bianchi HA, Tadano T, Paula CR, Hoffmann-Santos HD, Leite DP. Factors related to oral candidiasis in elderly users and non-users of removable dental prostheses. Rev. Inst. Med. Trop. 2016;58(17):1-5.

15- Jainkittivong A, Aneksuk V, Langlais RP. Oral mucosal lesions in denture wearers.Gerodontology. 2010;27(1):26-32.

16- Ferreira RC, Magalhães CS, Moreira AN. Oral mucosal alterations among the institutionalized elderly in Brazil.Braz Oral Res. 2010;24(3):296-302.

17- Coelho CMP, Zucoloto S, Lopes RA. Denture-induced fibrous inflammatory hyperplasia: a retrospective study in a school of dentistry. Int $\mathrm{J}$ Prosthodont. 2000;13:148-51.

18- Carli JP, Giaretta BM, Vieira RR, Linden MS, Ghizoni JS, Pereira JR. Lesões bucais relacionadas ao uso de próteses dentárias removíveis. Salusvist. 2013;32(1):103-15.

19- Scully C. Medicina Oral e maxilofacial: Bases do diagnóstico e tratamento. 2. ed. Rio de Janeiro: Elsevier; 2009, 392.

20- Neville BW, et al. Patologia oral e maxilofacial. 2. ed. Rio de Janeiro: Guanabara Koogan; 2008.

21- Alves NC, Gonçalves HHSB. Estudo descritivo da ocorrência de hiperplasias fibrosas inflamatórias observadas no Serviço do Laboratório de Histopatologia Bucal da Faculdade de Odontologia de Marília.Rev Paul Odonto.2005;4:4-8.

\section{Recebido em: 15/04/2016 / Aprovado em: 10/06/2016}

\section{Marília Heffer Cantisano}

Departamento de Diagnóstico e Terapêutica, Faculdade de Odontologia, Universidade do Estado do Rio de Janeiro

Boulevard 28 de Setembro, 157, Vila Isabel

Rio de Janeiro/RJ, Brazil - CEP: 20551-030

E-mail: mcantisano@terra.com.br 